\title{
The Impact of CBI on English Majors' Vocabulary Learning
}

\author{
$\mathrm{Si} \mathrm{Li} i^{1, *}$ \\ ${ }^{1}$ School of Foreign Languages, Dalian Neusoft University of Information, Dalian, Liaoning 116023, China \\ *Corresponding author.Email: lisi@neusoft.edu.cn
}

\begin{abstract}
Content-based instruction is a teaching approach emerged from Communicative Language Teaching. Previous studies have been made on CBI and its impact on students' learning pronunciation or reading comprehension. To further investigate the impact of CBI on students' language skill learning, the aim of this paper is to explore the impact of CBI on English Majors' vocabulary learning. A mixed method of quantitative and qualitative methods is used to collect data. Finally, the finding of the research is that CBI has a positive impact on students' vocabulary learning.
\end{abstract}

Keywords: Content-based Instruction, language skill, vocabulary learning

\section{INTRODUCTION}

\subsection{Background of This Research}

Traditional language teaching pays more attention to formbased teaching methodologies such as Grammar Translation [1] and Presentation-Practice-Production (PPP) $[2,3]$. Since $1960 \mathrm{~s}$, quite a few new language teaching methods emerged from America and Canada, for instance, Communicative Language Teaching (CLT), Task-based Language Teaching (TBLT) and Content-based Instruction (CBI), all of which are meaning-formed approaches. [3 - 6] However, too much emphasis on drills and language repetitions may make language learners lose motivation. In this context, the emergence of CBI which combines content teaching with language skill teaching seems to address the problem.

\subsection{Significance of This Research}

During long period of time, students of English Majors in China enhance their English skills mainly by learning relevant skill-oriented courses, like listening, reading, speaking, writing and translating. Nevertheless, too much emphasis on skill training may lead to students' low communicative competence and poor critical thinking. In addition, it may have little influence on their intercultural communication and expansion of humanistic knowledge. This research focuses on the influence of English Majors' professional skills under content-based courses, namely the impact on students' vocabulary learning, and also, feedback is collected on how students perceive language learning under CBI courses, whether the courses are beneficial to their English learning and whether there is anything that needs to be improved.

\subsection{Objectives of This Research}

This study intended to explore the impacts of CBI on English majors' lexical competence, which was based on the teaching reform of Grade 2008 in the School of English Studies in DLUFL (Dalian University of Foreign Languages). It investigated the following two aspects: one is the impact of CBI on English Majors' vocabulary learning; the other is the main difficulties and solutions that students encounter in the process of learning CBI courses.

\subsection{Thesis}

The researcher makes a hypothesis that CBI courses have some positive impacts on English majors' vocabulary learning, especially in terms of enlarging their vocabulary. To prove the hypothesis, the researcher invites students of English majors from fourth-year as the informants, from whom one experimental class and one control class are selected. The researcher compares their lexical competence by making the two classes take the same vocabulary test and in order to obtain the perspectives and suggestions on students' vocabulary learning under CBI courses, questionnaires and interviews are made in the experimental class.

\section{LITERATURE REVIEW}

\subsection{CBI and Vocabulary Learning}

Content-based Instruction (CBI) has been defined as "the teaching of content or information in the language being learned with little or no direct or explicit effort to teach the 
language itself separately from the content being taught" [5]. It emerged from language immersion education in Canada in 1965, which proved a success with the French immersion education in a second language context. Following the suit in the coming years, North American countries, as well as most European countries were eagerly and enthusiastically engaged in the research of immersion education both theoretically and practically. Up to 1980s, an increasing number of schools of both the East and the West, from kindergarten to tertiary education adopted a kind of educational approach similar to the immersion education. CBI has now spread to EFL classrooms around the world where teachers are discovering that their students express a preference for $\mathrm{CBI}$ and are excited to learn English in this way.

CBI prioritizes content and communicative actions over language learning, and students learn about content in the target language. It also abandons the idea of teaching language isolated, by combining language skills and knowledge to enhance learners' language proficiency and develop their communicative competence through learning knowledge in subject areas, such as geography, history and culture. $[5,8]$

\subsection{Vocabulary Learning}

According to Larsen-Freeman and Anderson [7], of the three significant elements - sound, grammar and vocabulary that a language is composed of, vocabulary plays a significant role. No matter whether it is in one's native language or second language, vocabulary is a tool and a means of effective interaction. If language is compared to a house, grammar can be compared to its framework and vocabulary can be compared to its building blocks. Second language researchers, and scholars have pointed that that lexical competence, grammar and pronunciation are fundamental for effective communication. $[5,7]$

Research on vocabulary learning ranges from concept of vocabulary to vocabulary learning strategies. Knowing a word is considered as a complex process in which it contains mastering its pronunciation, spelling, pragmatic and semantic category [8]. Oxford [9] divided vocabulary learning strategies into four categories: memory, social, cognitive and metacognitive. In terms of memory strategies, learners master new words through connecting new concepts with their prior knowledge. Social strategies refer to mastering new vocabulary by communicating with individuals. Taking advantage of cognitive strategies is a process of learning new vocabulary through transformation of the target language. Finally, making use of metacognitive strategies is to learn the new words consciously and plan, monitor and evaluate the optimal method of acquiring those words.

\subsection{Previous Studies}

Quite a few previous studies have been made to investigate how to balance traditional English professional skills under CBI courses. For instance, Liu Dan and Chang Junyue [10] made a research on the impact of Contentbased instruction on students' learning pronunciation at the fundamental stage. By setting an experimental class and a control class they found that there is no significant difference in experimental class and control class after the pre-test and post-test, and the impact of CBI on students' learning pronunciation is significantly positive in general. Chang Jueyue, Liu Xiaoqu and Deng Yaochen [11] studied the impacts of Content-based instruction reform on students' reading comprehension. The findings of their research indicated that $\mathrm{CBI}$ approach has a positive influence on English Majors' reading skill improvement especially extensive reading and significantly positive influence on learners' knowledge acquisition in the content areas. Zhao Xiuyan, Xia Yang and Chang Junyue [12] reported the CBI curriculum reform in Dalian University of Foreign Languages indicating that CBI courses enhanced students' performance in subject matter, and the positive potential in improving learners' language proficiency.

\subsection{Necessity for Further Research}

The above research was conducted among English major students at the fundamental stage focusing on the impact of CBI on pronunciation learning, reading comprehension and subject matter. The aim of this paper is to further investigate the impact of CBI on English majors from the perspective of lexical learning.

\section{RESEARCH METHOD}

\subsection{Research Questions}

The key research questions addressed in this essay are as follows:

(1) What are the impacts of CBI on English majors' vocabulary learning?

(2) What do informants see as the difficulties in learning CBI courses?

\subsection{Informants}

There are total 58 students who participated in the survey, among whom 49 are female, and 9 male, ranging 23 24 in age. They were students from one experimental class (Class 2) and one control class (Class 4) of English Majors of Grade 2008 in DLUFL (Dalian University of Foreign Languages). The reason for choosing the two classes among seniors was that there were only four experimental 
classes in Grade 2008 who learned courses including American History, American Geography and Culture and alternative series of $\mathrm{CBI}$ courses. The others took traditional courses including Comprehensive English, Advanced English and English Grammar, etc. However, the freshmen, sophomores and juniors had all experienced CBI reform, so contrast cannot be made among them. The experimental class and control class are all English Major students specializing in Advanced Translation and all the informants learned CBI courses for 3 years and a half. They had learned general theories of CBI and relevant CBI courses at the fundamental and advanced stage.

\subsection{Procedure and Data Collection}

In order to collect data, a mix method of qualitative and quantitative research was used including test, questionnaire and interview. At the first stage, all the informants accomplished a vocabulary competency test consisting of 50-item lexical multiple questions selected from Test for English Majors (Band 4). After the test, they completed a questionnaire concerning the difficulties in learning CBI courses. Finally, students were classified into two categories: high lexical competence and low lexical competence according to their test marks. And then 8 students from the above two categories were selected to attend a semi-structured interview regarding their perspectives of main difficulties in learning CBI courses. The interview was undertaken with the complete consent of the informants and they are not required to tell their names. Interviews with students lasted for around 40-50 minutes, were taped, transcribed, and returned for verification

\section{RESULTS AND FINDINGS}

\subsection{Impact of CBI on English Majors' Vocabulary Competence}

Table 1: Mean scores of the test of two groups of subjects

\begin{tabular}{|c|c|c|}
\hline & $\begin{array}{c}\text { Experimental } \\
\text { group }\end{array}$ & $\begin{array}{c}\text { Control } \\
\text { group }\end{array}$ \\
\hline Mean & 89 & 81 \\
\hline
\end{tabular}

According to Table 1, the mean score of the experimental group is 89 , while the control group's mean score is 81 . The Experimental group is 8 score higher than the Control group. In general, the score reflects that CBI courses have positive impact on English majors' vocabulary competence.

\subsection{Main Difficulties in Learning CBI Courses}

The first question on the questionnaire is a multiple-choice one. The question is that when you learned CBI courses, your obstacles were as follows: A. Vocabulary in the text B. Grammar in the text C. Unfamiliarity with the background knowledge D. Reading comprehension in the workbook E. Proofreading F. Writing

Table 2 The percentage of learning obstacles of the subjects (30)

\begin{tabular}{|c|c|c|}
\hline Item & Number & Percentage \\
\hline Vocabulary in the text & 19 & $63.33 \%$ \\
\hline Grammar in the text & 5 & $16.67 \%$ \\
\hline $\begin{array}{c}\text { Unfamiliarity with the } \\
\text { background knowledge }\end{array}$ & 24 & $80 \%$ \\
\hline $\begin{array}{c}\text { Reading comprehension } \\
\text { in the workbook }\end{array}$ & 7 & $23.33 \%$ \\
\hline Proofreading & 13 & $43.33 \%$ \\
\hline Writing & 10 & $33.33 \%$ \\
\hline
\end{tabular}

As shown in Table 2, 24 students (80\%) regard unfamiliarity with the background knowledge as the biggest learning obstacle, which indicates that CBI courses, for instance, British history and geography may cover large quantities of background information and terminologies. Learners should make good preview in order to learn the courses well. According to Table 2, vocabulary in the text is seen as the second learning difficulty. As the informant with the highest test score puts it: "I spend most of time reading the textbook and looking up all the words I didn't know before each lecture." However, grammar in the text seems to be the easiest task for learners with the lowest percentage of $16.67 \%$, or it may indicate that students may concentrate little on grammar when learning CBI courses. Alternative items including proofreading, writing, and reading comprehension in the workbook are not considered as difficulties accounting for $43.33 \%, 33.33 \%$ and $23.33 \%$ respectively.

Among 30 students who learned CBI courses, 28 of them stated that they enjoyed the learning process. As one informant put it: "Although it takes me long time to preview the text and accomplish the further reading list, I do enjoy CBI courses since I feel the content is interesting. I feel like learning British history and geography rather than English. It's different from the language skill learning in high school."

\section{CONCLUSION}

The finding of the research is that the impact of CBI has a positive impact on students' vocabulary learning. Overall, 
it shows that $\mathrm{CBI}$ is a teaching method that emphasizes learning about something rather than learning about language, and main focus of students is on the understanding of content and vocabulary. Since CBI is a meaning-formed approach, further study could be conducted on how to balance content teaching and language skills teaching. Besides, future research can be carried out from the perspective of balancing content teaching and writing skill teaching. It also should be noted that no matter CBI or TBLT, they are teaching methods first used by American and Canadian teachers and researchers based on the fact that most students in overseas universities are small-sized. However, the college English teaching in China is mainly large-sized with 40 students or more. In this context, how to conduct CBI in large-size context may need further investigation.

\section{REFERENCES}

[1] J. Harmer, The Practice of English Language Teaching, Longman, 2007.

[2] D. Willis, Accuracy, fluency and conformity, in: J. Willis, D. Willis (Eds.), Challenge and Change in Language Teaching, Oxford, Heinemann, 1996, pp. 4451.

[3] D. Carless, Revisiting the TBLT versus PPP debate: Voices from Hong Kong. Asian Journal of English Language Teaching, 19 (2009) 49-66. DOI: https://doi.org/10.1.1.707.9280

[4] R. Ellis, Task-based language teaching. Cambridge: Cambridge University Press, 2003.

[5] J. C. Richards, T. H. Rodgers, Approaches and Methods in Language Teaching, Cambridge University Press, 2001.

[6] S. Li, The theoretical analysis of communicative language teaching from the perspective of input, output and interaction. Overseas English, 23(2007)249-250.

[7] D. Larsen-Freeman, M. Anderson, Techniques and Principles in Language Teaching, Oxford University Press, 2011.

[8] E. Bada, Z. Okan, Students' language learning preferences. TESL - EJ, 4 (2000)1-15.

[9] R-L. Oxford, Language Learning Strategies: What Every Teacher Should Know, Heinle and Heinle Publishers, 1990.

[10] D. Liu, J-Y. Chang. The impact of Content-based instruction on students' learning pronunciation at the fundamental stage. Journal of Guangdong University of Foreign Studies, 1 (2011) 75-80.

[11] J-Y. Chang, D. Liu, Y-C. Deng. Impacts of Content-based instruction reform on students' reading comprehension. Foreign Languages in China, 3 (2009) $40-48+53$.

[12] X-Y. Zhao, Y. Xia, J-Y. Chang. CBI curriculum reform: the effect on English majors at the fundamental stage. Foreign Languages and Their Teaching, 1 (2014) 47-53. 